\title{
A PRODUÇÃO DE LIVROS DIDÁTICOS COMO AÇÃO AFIRMATIVA NA EDUCAÇÃO DAS RELAÇÕES ÉTNICO-RACIAIS BRASILEIRAS DE CRIANÇAS NEGRAS EM BELÉM DO PARÁ
}

\author{
Jaime Junior da Silva Mendonça ${ }^{1}$ \\ Emanuela Santos dos Santos 2 \\ Domingos Conceição ${ }^{3}$
}

Resumo: Os objetivos deste artigo são relatar a experiência em produção de livros didáticos, dos autores acima e cumprir as exigências de modelo do "II Seminário sobre Cotas na UFPA", essa experiência é a tentativa de responder a uma constatação feita pelo artigo em questão, que apontou a inexistência de livros didáticos que tratassem da temática do negro, em especial da criança negra, como ferramenta educativa, que cuide da educação, da aprendizagem, do silêncio e do combate a invisibilidade e ao racismo, os livros escritos e apresentados pelo autores abrangem aspectos educacionais $e$ sociológicos, como: escola, família, trabalho, vida e o professor, as nossas referências são de alguns marcos regulatórios e autores especializados: Diretrizes e Base da Educação Nacional (2011), Diretrizes Curriculares a Lei 10.639/03 (2004) e Lei 11.645/08, Conceição (2003/2013), Cavelleiro (2003), Guimarães (2008) e Reinaldo Guimarães (2013). Os procedimentos metodológicos são dados bibliográficos, documentais, das experiências práticas de produção de livros e a atualização da literatura especializada, os resultados são: "ação afirmativa como limites das políticas universalistas" e "ações afirmativas compulsórias", compreensão e contribuições dos especialistas para o desenvolvimento, melhoramento e continuidade, que as críticas nos estimulem ao crescimento, a relevância social e científica, contribua com a superação do racismo em Belém, na Amazônia e no Brasil.

Palavras-chave: Criança Negra. Sociologia do Negro Amazônico. Produção de Livros Infanto-Juvenil.

\footnotetext{
${ }^{1}$ Graduando em Pedagogia da Universidade Federal do Pará - UFPA. E-mail: jaimejr@ hotmail.com.br.

${ }^{2}$ Graduada em Pedagogia da Universidade Federal do Pará - UFPA. E-mail: manufersrv@ outlook.com.

${ }^{3}$ Licenciado Pleno em Ciências Sociais/UFPA; Especialista em Docência do Ensino Superior/UFPA; Escritor de Literatura Infanto-juvenil; Membro do Grupo de Estudos em Educação Rural - GERU / ICED / UFPA e da Associação do Movimento Afrodescendente do Pará: MOCAMBO. E-mail: coisasdepreto@gmail.com.
} 


\section{CONTEXTO}

Os objetivos deste artigo são refletir sobre práticas concretas em produção de livros didáticos destinado ao público infanto-juvenil amazônico dos autores acima e cumprir as exigências estabelecidas pelo "II Seminário sobre Cotas na UFPA".

$\mathrm{O}$ artigo vai ser desenvolvido baseado no transcurso de todos os passos dados para produzir livros didáticos que é o procedimento da metodologia sobre relatos de experiência. Em seguida mostraremos as etapas estabelecidas para realizar essa experiência, são: a inexistência de livros sobre a temática do negro em Belém, a criação da personagem Negrinho do Pará, o processo de produção do livro Negrinho do Para e Uma produção de livros didáticos correspondentes à educação das relações étnico-raciais brasileiras.

O problema e a problemática do artigo podem ser constatados como sendo, respectivamente: como escrever um livro quando as fontes são quase inexistentes? Por que nas escolas de Belém não se usa livros que tratem da temática do negro? Por que se dá pouca importância para o assunto do negro? A abordagem teórica do artigo é baseada na sociologia e na educação, através dos marcos legais e de obras de autores especializados: Diretrizes e Base da Educação Nacional (2011), Diretrizes Curriculares a Lei 10.639/03 (2004), Cruz (1998), Cavelleiro (2003), Guimarães (2008) e Reinaldo Guimarães (2013). Consideramos essa experiência inédita do ponto de vista de ser uma ação concreta, porém ela pouco impactou na superação da lacuna identificada pela pesquisa que deu origem aos livros produzidos, ela pode ser considerada inovadora, mas não atendeu a demanda existente em Belém, porque não se tornou acessível, conhecida e o poder púbico que deveria ser o maior interessado não deu a devida importância, pois não investe e não incentiva esse tipo de trabalho, pelo menos é o nosso entendimento.

\section{DESCRIÇÃO DA EXPERIÊNCIA}

O procedimento metodológico deste artigo é o relato de prática de experiência de produção de livros didáticos, inicia com a organização de todo o material disponível para os primeiros passos à produção dos livros publicados, em seguida foi feito o levantamento de novas fontes bibliográficas e de documentos afins, revisão bibliográfica do assunto e o estabelecimento dos aspectos principais a serem abordados sobre a experiência.

Essa pesquisa foi realizada em 1994 em uma escola pública de Ensino Fundamental e Médio, e na "Escolinha do Centro de Estudo e Defesa do Negro do Pará - CEDENPA" 
durante a realização da pesquisa para desenvolver a "Monografia de Conclusão do Curso de Licenciatura em Ciências Sociais" do então estudante Domingos Conceição, percebeu que não havia livros didáticos produzidos em Belém sobre a temática do negro para ser usados na escola básica de Belém e pelo público infantil em geral, essa pesquisa contou com a participação de oito professores negros que trabalhavam com crianças, todos disseram que não tratavam do assunto porque não tinham domínio do mesmo, por não serem formados para tal, não possuíam material didático específico, mesmo os livros de história ou de estudo sociais existentes na escola ou que eram de seu conhecimento, quando faziam referência a temática do negro, se relacionavam as datas comemorativas. O CEDENPA tratava melhor do tema por ter interesse de fazê-lo, por tratasse de uma associação de negros e ter optado em criar uma escolinha que pudesse contribuir no combate ao racismo através da educação, contudo os livros usados pelo CEDENPA tinha grande parte de sua produção fora de Belém, o que naquele momento nos pareceu um absurdo, pois não conseguíamos entender o porquê.

Mesmo esses livros vindos de outros estados, os alunos entrevistados, reclamavam de que em geral a família presente no livro nunca era a família negra, quando apareciam imagens de crianças ou familiares negros no livro didático era de forma "caricaturada", "estereotipada", fazendo trabalhos inadequados, era uma "literatura de adulto", ou seja, eram autores escrevendo para pessoas adultas e não para a educação de crianças, naquele período percebemos que o nosso estudo podia ser de grande utilidade à sociedade como um todo e à população negra em especial, porém o entrave estava na necessidade de se fazer materiais didáticos para diminuir essa lacuna, mais vinha sempre à pergunta: como incluir a temática do negro no livro didático? Como fazer um livro que conseguisse pelo menos minimizar a falta de livros infanto-juvenil?

Quando decidimos escrever o livro, uma coisa nos preocupou com maior intensidade, a questão de uma personagem que tivesse a ver com a criança negra da Amazônia, logo nos veio à cabeça, o açaí, um fruto nativo da biodiversidade amazônica de uso alimentar comum, disponível a todos, porém no Pará ele existe em maior quantidade, por quê? Pelo fato do açaí ser um alimento saudável e entrar em qualquer casa, rica ou pobre, para nós tínhamos descoberto a personagem de nossa obra, mesmo assim resolvemos fazer um teste com o meu filho pequeno de quatro anos, ele esboçou alguns desenhos que diziam da família do açaí, com árvores de açaizeiros e figuras humanas. Fizemos outro teste, 
fizemos um pequeno texto sobre a lenda do açaí ${ }^{4}$, e, juntamente com o desenho de um grande pé de açaizeiro participamos da uma contação de histórias na Escola Anchieta para crianças de 4 a 6 anos, falando do açaí e elas adoraram o trabalho, então saímos dali decididos a buscar um ilustrador para construir uma proposta de personagem.

Na busca desse ilustrador encontramos todas as dificuldades possíveis, inclusive a má vontade desses profissionais, ou mais que isso, todos cobram quantias que em geral estão fora de nossas condições financeiras, conversei com vários colegas que já tinham escrito livros, todos apontavam dificuldades, principalmente porque eram poetas e eles entendem que escrever livros para crianças não é coisa de poeta. Com todas essas barreiras, decidimos manter a ideia central do livro como sendo uma metáfora do açaí, porém criamos uma família negra de 4 integrantes: pai e mãe, dois filhos (uma menina e um menino), sendo o menino a personagem principal do livro, dessa forma tornou-se mais fácil conseguir um ilustrador.

Quando conseguimos o ilustrador ele tinha dificuldade em ilustrar personagens negros, depois de contatar com vários profissionais conseguimos um rapaz muito jovem, mais que se interessou pelo assunto, após uma longa conversa e justificativa do porquê e da importância de fazer esse livro, ele propôs-se fazer um esboço e a partir desse esboço nós elegíamos o que fosse mais adequado ao nosso trabalho. Quando apresentamos para ele o que queríamos quase $90 \%$ dos textos e das sugestões de personagens para cada texto já estavam prontas, esse rapaz, passou em torno de duas semanas e nos entregou uma proposta para análise.

Após fazer a revisão e observações, dos personagens criados por ele, concluímos que era aquilo que estávamos buscando, nascia ali a criação imagética da personagem "Negrinho do Para", quando sentamos para conversar, tivemos poucas dificuldades de fazermos o contrato para o seu serviço, finalizamos o restante dos textos e das personagens que gostaríamos que fossem criados, num prazo de um pouco mais de um mês tudo ficou pronto.

A criação da personagem é uma das partes importantes do nosso primeiro livro, porém existem outras criações que dependem de outros profissionais, ou em alguns casos, pode ser o próprio ilustrador que cumpra essa tarefa, no caso do nosso livro um amigo juntou-se com o ilustrador e produziram juntas a diagramação eletrônica e todas as demais

\footnotetext{
${ }^{4}$ Era uma palmeira frondosa e exuberante, com sua beleza de mãe. Um belo dia, olhada por uma índia que passou a admira-la. E não parou mais para visita-la, naquele lugar que parecia encantado. Um dia para sua surpresa estava lá um cacho, embranquecido como um algodão [...] (Conceição,1999.).
} 
criações que seriam necessárias até o livro ficar definitivamente pronto para ser levado à gráfica e ser impresso, o nosso ilustrador chama-se Wagner Smith Santos, o criador da imagem visual da personagem "Negrinho do Para", nome oficial da nossa primeira obra, representada pelo garoto João, publicado e lançado no dia 19 de agosto de 2003

O processo de divulgação venda e trabalho prático com o livro foi feito de 2003 até 2011 da forma mais amadora possível, pois nós acreditávamos que essa era a forma correta de torná-lo conhecido, nesses oito anos de lançamento do livro fizemos vários outros lançamentos: na Feira Pan-Amazônica do Livro do Pará e em Macapá, em alguns eventos nacionais, participamos de algumas palestras e oficinas em escolas de Belém, o livro já foi usado pelo Colégio Santo Antônio para alunos de $4^{\mathrm{a}}$ e $5^{\mathrm{a}}$ série e também o livro exposto em algumas feiras em municípios fora de Belém, a SEMEC comprou 40 exemplares e a SEDUC comprou 150 exemplares, o que demonstra a pouca importância que se dá a obra de escritores paraenses, essa primeira edição está se esgotando.

Em 2010 quando finalizamos e publicamos o nosso segundo livro passamos a indagar- nos, pois ainda não tínhamos atentado para isso, para que estávamos escrevendo livros? Se era apenas uma contribuição militante à sociedade, ou profissional? Por quê? Porque nós pagávamos todas as despesas com a produção dos livros, reclamávamos que escrevíamos e não conseguíamos publicar e queria vender com sucesso os nossos livros, mas evitávamos uma comercialização profissional no mercado do livro, foi então que pensamos em fazer um projeto de profissionalização, divulgação, comercialização e venda dos nossos livros para que pudessem conseguir recursos para continuar escrevendo e publicando novos livros. Em 2011, fizemos o Projeto de Comercialização dos Livros e uma das ações realizadas foi visitar e divulgar os livros nas escolas privadas de ensino fundamental e médio a segunda, ação do projeto, foi colocar os livros para serem vendidos em duas livrarias de Belém, alguns exemplares foram vendidos, em seguida, por conta de pouca saída, retiramolos dessas livrarias e não os colocamos mais.

\section{RESULTADOS}

Essa pesquisa gerou vários problemas a serem estudados e uma rica problemática, porém os livros que produzimos pouco mudou essa realidade, a maioria dela continua até aos nossos dias, sem previsão de mudança, além do problema como fazer um livro? O outro foi como um livro específico para crianças negras pode contribuir para diminuir o alto índice de crianças negras com baixa escolaridade em Belém? O primeiro, problema não solucionamos, 
porém mostramos neste artigo que conseguimos escrever e publicar dois livros o segundo, pode se dizer que é o mais complexo, mas vamos observar que há algumas alterações por iniciativas das políticas públicas e de ações de instituições de educação, assim como da luta políticas dos movimentos sociais negros que são os principais protagonistas de ações positivas e afirmativas. Com relação à problemática apontada na pesquisa, por exemplo: a quem compete a responsabilidade de solucionar esse problema que afeta sob maneira, toda a sociedade paraense? Por que não tem livro sobre o negro? Quem financia o livro? Quem distribui o livro? Quem compra? São questões que envolvem um conjunto de atores e instituições.

Daí veio os primeiros textos escritos por nós, vimos o tipo de linguagem a ser usado, o enredo da estória ou história, o nome do livro, com as leituras que fomos fazendo começou a ficar mais fácil de escrever, verificamos que os livros usados em Belém são característicos das Regiões Sul e Sudeste do Brasil, constatamos que se pensava que na Amazônia não tinha negro, apenas "índios", decidimos fazer o livro por temas: família, escola, professor, trabalho e vida, explorando a prática do educador, a realidade da criança, com a finalidade de dialogar com o Brasil tendo a Amazônia como referência para entender a criança brasileira, negra e não negra. Com a definição de nossa personagem central do livro, entendemos melhor o desenrolar da experiência em questão.

O que trazemos para a arena desta discussão, denominada de "ausência de materiais didáticos específicos" (Conceição, 1994), para ser usado pelas crianças em idade escolar e da falta de crianças negras nos livros existentes em outros estados, é o que em nossa Monografia definimos como "lacuna", ou seja, a pesquisa feita naquele contexto, mesmo que não tenha dado conta de identificar tudo o que existia na rede municipal de Belém e na rede Estadual, porém as mostras extraídas da escola estadual, da escolinha do CEDENPA e dos oito professores entrevistados, nos dá credibilidade de afirmar, que o que vimos pode provisoriamente ser dito que havia a inexistência de uma literatura adequada ao público infanto-juvenil em Belém.

Diante disso é preciso juntar os escritores, os professores, os pesquisadores, os estudantes e os movimentos sociais, e busquem os apoios necessários para implementar a Lei $\mathrm{n}^{\circ} 10.639 / 03$, e tornar reconhecida e validado os nossos livros como material didático especializados, financiado e utilizados nas escolas públicas do Estado e de Belém. 


\section{REFERÊNCIAS BIBLIOGRÁFICAS}

BRASIL. Lei de diretrizes e base da educação, - 7. Ed. - Brasília: Senado Federal, Subsecretaria de Edições Técnicas, 2011.

BRASIL. Lei Federal nª 12.288/10, Estatuto da Igualdade Racial, - Brasília, 2011.

BRASIL. Ministério da Educação/ Secretaria de Educação Continuada, Alfabetização e Diversidade. Orientações ações para a educação das relações étnico-raciais, Brasília: SECAD, 2006.

CARRASCO, Walcyr. Irmão negro. São Paulo Moderna, 1995.

CAVALlEIRO, Eliana dos Santos. Do silêncio do lar ao silêncio escolar: racismo, preconceito e discriminação na educação infantil. 2ed. - São Paulo: Contesto, 2003.

CONCEIÇÃO, Domingos. A educação do negro no livro didático. Belém, Monografia, UFPA, 1997.

CONCEIÇÃO, Domingos. A Educação do negro no livro didático. Belém, UFPA, 1996. Diretrizes curriculares nacionais para a educação das relações étnico-raciais e para o ensino de história e cultura afro-brasileira e africana: Lei Federal $\mathrm{n}^{\mathrm{a}}$ 10.639/03/ Ministério da Educação,- Brasília, 2004.

MACHADO, Ana Maria. Menina bonita do laço de fita: $7^{\circ}$ ed. São Paulo, Ática, 2000. 